\title{
E-cadherin: A potential biomarker of colorectal cancer prognosis (Review)
}

\author{
NIKI CHRISTOU ${ }^{1,2}$, AURÉLIE PERRAUD ${ }^{1,2}$, SABRINA BLONDY ${ }^{1}$, \\ MARIE-ODILE JAUBERTEAU ${ }^{1}$, SERGE BATTU ${ }^{1,2}$ and MURIEL MATHONNET ${ }^{1,2}$ \\ ${ }^{1}$ Cellular Homeostasis and Pathology, Faculty of Medicine, GEIST Institute, University of Limoges, F-87025 Limoges; \\ ${ }^{2}$ General, Endocrine and Digestive Surgery Department, University Hospital of Limoges, F-87042 Limoges, France
}

Received October 15, 2016; Accepted February 1, 2017

DOI: $10.3892 / \mathrm{ol} .2017 .6063$

\begin{abstract}
Colorectal cancer (CRC) is a common and lethal disease. It is the third most common type of cancer in the world, behind lung and breast cancer, with almost 1.4 million new cases diagnosed in 2012. The risk of developing $\mathrm{CRC}$ is influenced by environmental and genetic factors. Adenocarcinomas comprise the vast majority (98\%) of CRCs. A patient's likelihood of survival is associated with the tumor stage at the time of diagnosis. With regular screening, CRC can be identified early, when treatment is the most effective. However, CRC is typically asymptomatic until the advanced stages. The combination of the absence of symptoms and current screening methodology results in a significant number of patients being diagnosed in advanced stages. The purpose of the present review is to discuss and summarize the biomarkers linked to CRC progression, particularly the controversial E-cadherin, which is a calcium-dependent cell-cell adhesion molecule involved in the mesenchymal-epithelial transition.
\end{abstract}

\section{Contents}

1. Introduction

2. CRC and biomarkers

3. E-cadherin and cancer

4. E-cadherin and colon cancer

5. Conclusion

\section{Introduction}

Colorectal cancer (CRC) is a prominent cause of mortality worldwide (1). It is surgically curable in early stages, when it is localized or limited to loco-regional invasion; however,the

Correspondence to: Dr Niki Christou, Cellular Homeostasis and Pathology, Faculty of Medicine, GEIST Institute, University of Limoges, 2 Rue du Dr Marcland, F-87025 Limoges, France

E-mail: christou.niki19@gmail.com

Key words: colorectal cancer, biomarkers, E-cadherin protein metastatic stages are associated with a high mortality rate (2). According to GLOBOCAN estimates (1), there were $1,360,602$ new cases of CRC worldwide in 2012, making it the third most common type of cancer worldwide and accounting for $9.7 \%$ of all cases of cancer that were not non-melanoma skin cancer (2). The majority of CRCs are adenocarcinomas. When these are diagnosed early, the prognosis is good: The 5 -year relative survival rate is $91 \%$ for localized cancer and $70 \%$ for cancer with loco-regional invasion. However, the 5-year survival rate is $\sim 11 \%$ in metastatic cases, which includes $\sim 25 \%$ of patients at the point of diagnosis (3) The rate of CRC mortality has decreased over the last 20 years due to advances in disease management, including earlier diagnosis and improved treatment modalities. However, a lack of reliable methods for the early detection of CRC is impacting patient prognoses (4).

At present, carcinoembryonic antigen (CEA), a <200-kilodalton $(\mathrm{kDa})$ glycoprotein that acts to mediate cell adhesion in cancer, is used in the initial assessment and monitoring of CRC (5). It was first identified in the blood serum of patients with CRC (6). However, $30 \%$ of cases of CRC recurrence do not produce CEA, irrespective of the amount associated with the original disease. Furthermore, it is estimated that $44 \%$ of patients with normal CEA levels prior to surgery have an increased CEA level in disease recurrence (7). The diagnostic value of CEA also varies according to the site. The sensitivity of CEA for the detection of hepatic and retroperitoneal metastases is greater than for the detection of lung metastases; sensitivity is also improved in cases of multiple recurrences compared with a single recurrence. A number of potential diagnostic and prognostic biomarkers for CRC have been evaluated thus far (Table I), including cytokines, chemokines and enzymes (8-14).

\section{CRC and biomarkers}

Blood serum biomarkers are of interest for the screening and monitoring of disease as they do not require invasive procedures and may facilitate rapid detection (8). CRC biomarkers in the blood include circulating tumor cells, DNA, RNA and proteins (8). In Table I, a number of serum biomarkers that may be used for the early detection or monitoring of CRC are summarized. 
Circulating tumor cells in CRC have been validated as prognostic markers for advanced disease and are associated with a poor overall survival time (15). The US Food and Drug Administration has validated them as monitoring markers, as they may predict response to treatment (16). Circulating DNA is also considered as a promising type of prognostic marker. For example, the detection of a Kirsten rat sarcoma mutation preoperatively, or its persistence subsequent to surgery, is associated with a poor prognosis (17).

These biomarkers are accessible with simple and rapid methods throughout the fluctuating course of the disease. A number of studies $(15,17)$ have demonstrated the utility of these biomarkers in prognosis and monitoring, and as theranostic markers, and recommend their routine use in the near future. However, according to consensus-based recommendations from the American Society of Clinical Oncology (18), only CEA levels should be monitored preoperatively to assist in staging and surgical planning. There is currently no biomarker for the early detection of CRC, with negative consequences for patient prognosis (10).

\section{E-cadherin and cancer}

Similar to CEA, one of the putative protein biomarkers for the prediction of tumor progression, E-cadherin, is an adhesion molecule. The loss of cell adhesion is one of the mechanisms underlying cancer invasion and progression (19).

E cadherin belongs to the 'classical' or type-I cadherin subfamily. A total of 16 molecules of $\sim 120 \mathrm{kDa}$ each have been identified in this subfamily. Four subclasses exist: Non-neuronal epithelial (E-), placental (P-), neuronal (N-) and retinal (R-) cadherins. E-cadherin is encoded by the $\mathrm{CDHI}$ gene; it is a calcium-dependent transmembrane glycoprotein that is localized to adherens junctions at the basolateral surface of epithelial cells, and is involved in cell-cell interactions, including in cancer (20).

The E-cadherin molecule is composed of a cytoplasmic domain, a single-pass transmembrane domain and an extracellular domain that consists of five cadherin-motif tandem repeat subdomains that have putative calcium binding sites (21). The cytoplasmic domain interacts with catenin molecules, including $\beta$-catenin or plakoglobin (also called $\gamma$-catenin), to mediate its binding to actin filaments of the cytoskeleton (22). Either $\beta$-catenin or plakoglobin may bind $\alpha$-catenin, giving rise to two distinct cadherin-catenin complexes. $\alpha$-catenin then links these two complexes to actin filaments. This anchorage has been speculated to be regulated by tyrosine phosphorylation (23) (Fig. 1). $\beta$-catenin may also bind to the cytoplasmic domain of the epidermal growth factor receptor (EGFR) (24).

E-cadherin downregulation is associated with certain malignant characteristics, including tumor progression, loss of differentiation, invasion and metastasis $(25,26)$. E-cadherin may be inactivated in cancer by mechanisms including mutations, epigenetic silencing, and increased endocytosis and proteolysis (22). Studies on the loss of heterozygosity in chromosome 16q21-22 have linked E-cadherin downregulation to gastric, prostate, hepatocellular and esophageal carcinomas (27). Despite this, E-cadherin mutations are rare in carcinomas of the bladder, colon, endometrium, lung, esophagus, ovary and thyroid, and in intra-hepatic cholangiocarcinoma (28).
Promoter hypermethylation is an important epigenetic event associated with the loss of E-cadherin expression (29). Several suppressors of E-cadherin transcription have been associated with the progression of multiple cancer types. For example, increased SNAI1 expression, as is common in ductal breast carcinoma, is strongly associated with reduced E-cadherin gene expression (30).

Other mechanisms may disturb normal E-cadherin function under pathological conditions. E-cadherin is removed from the plasma membrane by endocytosis and recycled to the sites of novel cell-cell contacts. Abnormal activation of proto-oncogenes, including Src and EGFR, results in increased phosphorylation of tyrosine residues in the cytoplasmic domain of E-cadherin (Fig. 2), leading to the recruitment of the E3-ubiquitin-protein ligase Hakai and subsequently enhancing the endocytosis and ubiquitin-dependent degradation of E-cadherin (31).

Matrix metalloproteinases (MMPs; Fig. 3), including stromelysin-1, matrilysin, MMP9 and MT1-MMP, cleave E-cadherin ectodomains close to the plasma membrane (32). Several other proteases, including serine protease kallikrein-7, may be involved. Pancreatic adenocarcinomas frequently overexpress kallikrein-7, which facilitates tumor cell invasiveness via the cleavage and release of soluble E-cadherin (33). Another example of E-cadherin disturbance contributing to tumor malignancy is peritoneal metastasis in advanced epithelial ovarian cancer, where calpain-mediated E-cadherin fragmentation appears to promote intraperitoneal cancer progression (34). In the human colon cancer cell line HT-29, syndecan-2, a cell-surface heparan sulfate proteoglycan induces extracellular shedding of E-cadherin and supports the acquisition of a fibroblast-like morphology by regulating MMP-7 expression (35).

Post-translational modifications of E-cadherin have also been described. The $O$-mannosylation of E-cadherin is crucial for its adhesive functions in homeostasis. Carvalho et al (36) demonstrated that E-cadherin underwent a decrease in $O$-mannosylation in gastric carcinoma that resulted in the impairment of its function through interference with its cell membrane localization and, subsequently, with the assembly and competence of adherens junctions.

Recently, Petrova et al (37) demonstrated that the metastasis of an E-cadherin-expressing mammary cell from the mammary gland to the lung is dependent on reduced E-cadherin adhesive function. An activating monoclonal antibody against E-cadherin that induced a high-adhesive state significantly reduced the number of cells that metastasized to the lung. Thus, stimulating the activity of E-cadherin on the cell surface inhibits metastatic progression, suggesting that the downregulation of adhesion in these tumor cells contributes to their metastatic potential.

\section{E-cadherin and colon cancer}

Recent studies have identified that the loss of expression of E-cadherin and colon cancer invasiveness are associated (38); however, this is rarely attributed to E-cadherin gene mutation (39). The mechanism for downregulation is more frequently post-translational modifications, as suggested by Kitadai et al (40). 
Table I. Examples of biomarkers for colorectal cancer.

\begin{tabular}{lll}
\hline Author (year) & \multicolumn{1}{c}{ Marker } & \multicolumn{1}{c}{ Sample type } \\
\hline Yörüker et al $(2016)$ & DNA integrity & Serum/plasma \\
Fan et al $(2014)$ & $\alpha-2-H S$ glycol protein & Serum \\
Newton et al $(2012)$ & Carcinoembryonic antigen & Serum \\
Wang et al $(2012)$ & MicroRNA-21 & Serum/plasma \\
Cohen et al $(2009)$ & Circulating tumor cells & Peripheral blood \\
Taback et al $(2006)$ & Microsatellite instability & Serum/plasma \\
Bazan et al $(2006)$ & KRas mutations & Serum/plasma
\end{tabular}

KRas, Kirsten rat sarcoma.

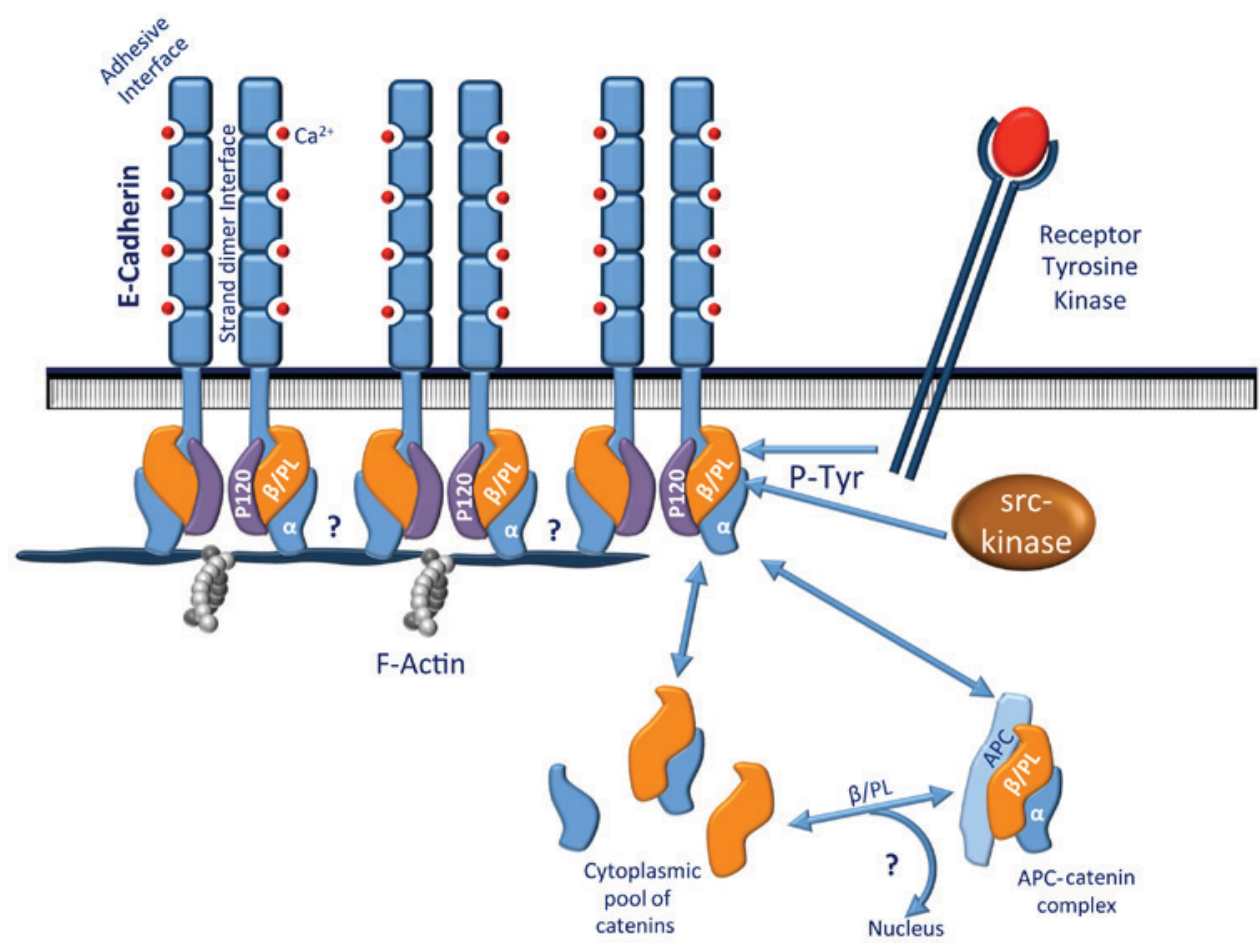

Figure 1. Interaction of the E-cadherin-catenin complex. The cadherin adhesion system is linked to the actin-based cytoskeleton via catenins. The figure illustrates protein interactions between different catenin pools, E cadherin and p120-catenin (p120), regulating the dynamic assembly and disassembly of the cadherin-catenin complex and its function in signal transduction. $\beta / \mathrm{PL}, \beta$-catenin or plakoglobin; $\alpha, \alpha$-catenin; P-Tyr, tyrosine phosphorylation; APC, adenomatosis polyposis coli-Wnt signaling pathway regulator.

A number of studies have identified E-cadherin as a good biomarker for CRC prognosis. In the earliest study, tissues samples were examined. Invasion and metastasis were revealed to be associated with the reduction of $\alpha$-catenin alone or with reduction of $\alpha$-catenin and E-cadherin co-expression, not purely with E-cadherin expression alone (41). More recent studies were performed on sera samples. In a study by Velikova et al (42), soluble E-cadherin concentrations in patients with CRC were not significantly increased compared with those of the control group. In another study conducted with 36 patients with CRC, E-cadherin was demonstrated to be a good marker of CRC. However, it lacked the required specificity to predict tumor progression; concentrations of E-cadherin were higher for patients with CRC as well as for patients with benign tumors (43). In another study, Weiss et al (44) compared soluble E-cadherin levels in 59 patients with CRC to the levels in patients with other conditions, including colorectal adenomas, inflammatory bowel disease or familial adenomatous polyposis. There was a significant elevation of soluble E-cadherin levels in patients with advanced CRC (stages III and IV). This study suggested a potential application for soluble E-cadherin as a diagnostic marker for monitoring disease in patients with CEA-negative tumors (44). The largest study was conducted on 186 patients with CRC; a preoperatively elevated soluble E-cadherin level was associated with a worse prognosis (38). The study demonstrated that E-cadherin was a metastasis prediction marker and a pre-therapeutic prognostic marker for patients with CRC and hepatic metastases. All these data confirmed that soluble E-cadherin levels increase with advancing tumor stage $(38,41-44)$. 


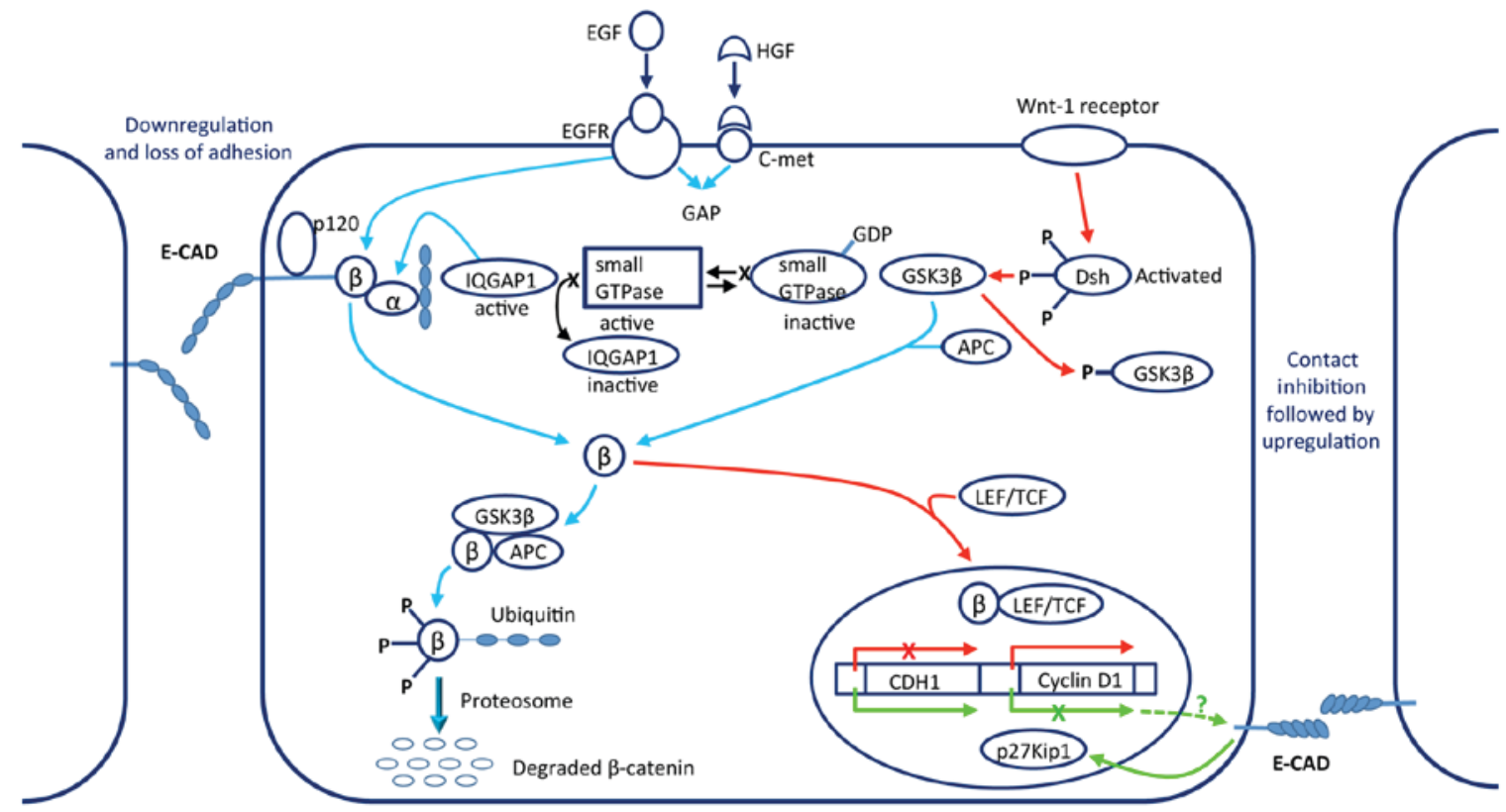

Figure 2. Operating mode of the E-cadherin-catenin complex in tumor metastasis. Stimulation of EGFR and c-Met receptors led to the translocation of B-catenin into the cytosolic pool where it can be degraded. If the Wnt1 pathway is activated at the same time as the other two pathways, the degradation of $\beta$-catenin is inhibited and it is translocated to the nucleus to combine with LEF/TCF, causing transcription of the cyclin D1 gene and downregulation of the $\mathrm{CDH1}$ gene. Reversal by way of contact inhibition is poorly understood. E-CAD, E-cadherin; EGF, epidermal growth factor; EGFR, epidermal growth factor receptor; HGF, hepatocyte growth factor; c-Met, hepatocyte growth factor receptor; GAP, GTPase activating protein; $\beta, \beta$-catenin; $\alpha, \alpha$-catenin; IQGAP1, IQ motif-containing GTPase activating protein 1; GDP, guanosine diphosphate; GSK3 $\beta$, glycogen synthase kinase 3 $\beta$; APC, adenomatosis polyposis coli Wnt signaling pathway regulator; P, phosphorylation group; Dsh, disheveled; LEF/TCF, lymphoid enhancer factor/T-cell factor family of transcription factors; $\mathrm{CDH} 1$, cadherin 1 (E-cadherin gene); p27Kip1, cyclin-dependent kinase inhibitor 1B.

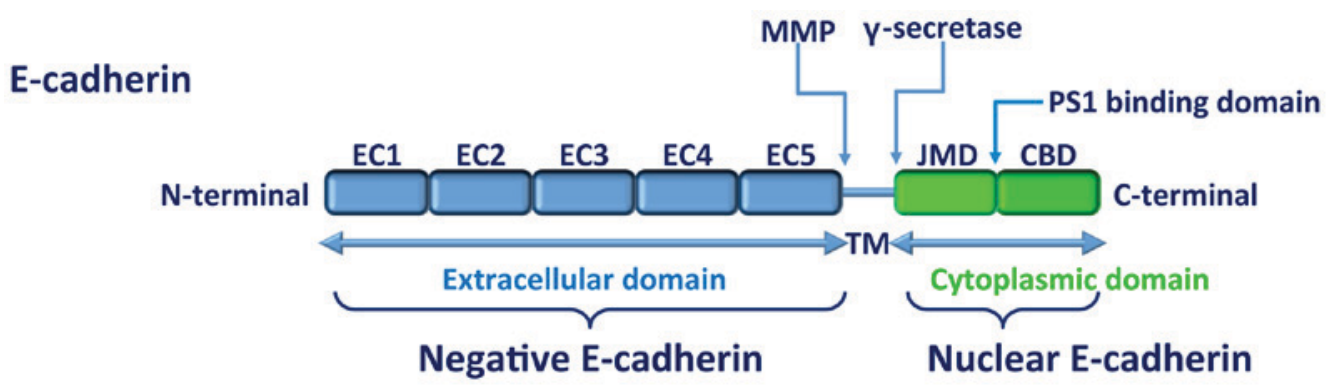

Figure 3. Schematic representation of E-cadherin protein. The protein contains ECs, a JMD and a CBD, together with cleavage sites for MMPs and $\gamma$-secretase, and a binding domain for PS1. EC, extracellular domain; JMD, juxtamembrane domain; CBD, catenin-binding domain; MMP, matrix metalloproteinase; PS1, presenilin-1; TM, transmembrane domain.

E-cadherin serves a crucial role in cell-cell adhesion and maintaining epithelial morphology. Loss of E-cadherin leads to the loss of epithelial differentiation and the acquisition of a motile and invasive phenotype (45). A recent study (46) enrolled patients with signet ring cell carcinoma, a rare type of colorectal adenocarcinoma with a worse prognosis than classical colorectal adenocarcinoma. The study demonstrated that patients with a loss of tumor E-cadherin expression had a lower survival time. Loss of E-cadherin expression was a significant, independent predictor for poor prognosis. The implications of E-cadherin in CRC progression has also been recently demonstrated (47): The expression of E-cadherin in 108 patients with CRC metastasis was lower than that in normal adjacent tissues, and was associated with tumor differentiation, invasion depth, lymph node metastasis and tumor stage. Furthermore, expression of E-cadherin prolonged the survival time of mice with patient-derived CRC xenografts (47).
As a consequence of this association, E-cadherin is a potential target for anticancer treatment. Chen et al (48) illustrated this; dimethoxy curcumin inhibited cell growth and enhanced E-cadherin expression in two CRC cell lines (HT-29 and SW480). In a CRC liver metastasis mouse model, the combination of a vascular disrupting agent with the anti-angiogenic drug sunitinib increased treatment efficacy; it reduced the number of viable tumor cells and prolonged animal survival time. E-cadherin staining was lower for the treated cells than for controls. The surviving tumor cells underwent a redistribution of E-cadherin from the cell junctions to the cytoplasm and nucleus (49) exhibiting epithelial-mesenchymal transition (EMT) and contributing to therapy resistance. Regorafenib (Stivarga ${ }^{\circledR}$ ) targets protein tyrosine phosphatase and is approved for the pharmacotherapy of CRC metastasis. Regorafenib also targets EMT; it directly activates SH2-domain-containing 
phosphatase 1 (SHP-1) to inhibit EMT. SHP-1 expression is positively correlated with E-cadherin expression, and is significantly correlated with the overall survival time of patients with CRC (50).

Furthermore, by upregulating E-cadherin expression, CRC risk may be reduced. E-cadherin expression was increased in patients supplemented with calcium and vitamin D (51). Calcium and vitamin D may thus be chemopreventive agents against CRC.

\section{Conclusion}

E-cadherin protein expression is associated with CRC tumor progression. The detection of soluble E-cadherin may allow the early detection of CRC and the monitoring of tumor progression. However, current tests lack sensitivity and specificity. Studies on larger cohorts may be illuminating in this area. Another possibility is to compare the levels of E-cadherin with those of other key molecules in CRC progression. A combination of key molecule levels may be more effective than one molecule alone.

\section{References}

1. Ferlay J, Soerjomataram I, Dikshit R, Eser S, Mathers C, Rebelo M, Parkin DM, Forman D and Bray F: Cancer incidence and mortality worldwide: Sources, methods and major patterns in GLOBOCAN 2012. Int J Cancer 136: E359-E386, 2015.

2. Faivre J, Lepage $\mathrm{C}$ and Viguier J: Cancer colorectal: Du diagnostic au dépistage. Gastroentérologie Clin Biol 33: 660-671, 2009.

3. Institut National Du Cancer (INCA): Les traitements du cancer du côlon, collection Guides patients Cancer info. INCA, 2010. http://www.e-cancer.fr/Patients-et-proches/Les-cancers/ Cancer-du-colon/Points-cles.

4. Rawson JB and Bapat B: Epigenetic biomarkers in colorectal cancer diagnostics. Expert Rev Mol Diagn 12: 499-509, 2012.

5. Hatakeyama K, Wakabayashi-Nakao K, Ohshima K, Sakura N, Yamaguchi K and Mochizuki T: Novel protein isoforms of carcinoembryonic antigen are secreted from pancreatic, gastric and colorectal cancer cells. BMC Res Notes 6: 381, 2013.

6. Gold P and Freedman SO: Specific carcinoembryonic antigens of the human digestive system. J Exp Med 122: 467-481, 1965.

7. Bast RC Jr, Ravdin P, Hayes DF, Bates S, Fritsche H Jr, Jessup JM, Kemeny N, Locker GY, Mennel RG and Somerfield MR; American Society of Clinical Oncology Tumor Markers Expert Panel: 2000, Update of recommendations for the use of tumor markers in breast and colorectal cancer: Clinical practice guidelines of the American society of clinical oncology. J Clin Oncol 19: 1865-1878, 2001.

8. Yörüker EE, Holdenrieder S and Gezer U: Blood-based biomarkers for diagnosis, prognosis and treatment of colorectal cancer. Clin Chim Acta 455: 26-32, 2016.

9. Fan F, Samuel S, Evans KW, Lu J, Xia L, Zhou Y, Sceusi E, Tozzi F, Ye XC, Mani SA and Ellis LM: Overexpression of Snail induces epithelial-mesenchymal transition and a cancer stem cell-like phenotype in human colorectal cancer cells. Cancer Med 1: 5-16, 2012.

10. Newton KF, Newman W and Hill J: Review of biomarkers in colorectal cancer. Colorectal Dis 14: 3-17, 2012.

11. Wang B and Zhang Q: The expression and clinical significance of circulating microRNA-21 in serum of five solid tumors. J Cancer Res Clin Oncol 138: 1659-1666, 2012.

12. Cohen SJ, Punt CJA, Iannotti N, Saidman BH, Sabbath KD, Gabrail NY, Picus J, Morse MA, Mitchell E, Miller MC, et al: Prognostic significance of circulating tumor cells in patients with metastatic colorectal cancer. Ann Oncol 20: 1223-1229, 2009.

13. Taback B, Saha S and Hoon DS: Comparative analysis of mesenteric and peripheral blood circulating tumor DNA in colorectal cancer patients. Ann N Y Acad Sci 1075: 197-203, 2006.
14. Bazan V, Bruno L, Augello C, Agnese V, Calò V, Corsale S, Gargano G, Terrasi M, Schirò V, Di Fede G, et al: Molecular detection of TP53, Ki-Ras and p16INK4A promoter methylation in plasma of patients with colorectal cancer and its association with prognosis. Results of a 3-year GOIM (Gruppo Oncologico dell'Italia Meridionale) prospective study. Ann Oncol 17 (Suppl 7): vii84-vii90, 2006.

15. Rahbari NN, Aigner M, Thorlund K, Mollberg N, Motschall E, Jensen K, Diener MK, Büchler MW, Koch M and Weitz J: Meta-analysis shows that detection of circulating tumor cells indicates poor prognosis in patients with colorectal cancer. Gastroenterology 138: 1714-1726, 2010.

16. Abdallah EA, Fanelli MF, Buim ME, Machado Netto MC, Gasparini Junior JL, Souza E Silva V, Dettino AL, Mingues NB, Romero JV, Ocea LM, et al: Thymidylate synthase expression in circulating tumor cells: A new tool to predict 5-fluorouracil resistance in metastatic colorectal cancer patients. Int J Cancer 137: 1397-1405, 2015.

17. Lecomte T, Berger A, Zinzindohoué F, Micard S, Landi B, Blons H, Beaune P, Cugnenc PH and Laurent-Puig P: Detection of free-circulating tumor-associated DNA in plasma of colorectal cancer patients and its association with prognosis. Int J Cancer 100: 542-548, 2002.

18. Locker GY, Hamilton S, Harris J, Jessup JM, Kemeny N, Macdonald JS, Somerfield MR, Hayes DF and Bast RC Jr; ASCO: ASCO 2006 update of recommendations for the use of tumor markers in gastrointestinal cancer. J Clin Oncol 24: 5313-5327, 2006.

19. Behrens J: The role of cell adhesion molecules in cancer invasion and metastasis. Breast Cancer Res Treat 24: 175-184, 1993.

20. Shiozaki H, Oka H, Inoue M, Tamura S and Monden M: E-cadherin mediated adhesion system in cancer cells. Cancer 77: 1605-1613, 1996.

21. Nagar B, Overduin M, Ikura M and Rini JM: Structural basis of calcium-induced E-cadherin rigidification and dimerization. Nature 380: 360-364, 1996.

22. Van Roya F and Berxb G: The cell-cell adhesion molecule E-cadherin. Cell Mol Life Sci 65: 3756-3788, 2008.

23. Aberle H, Schwartz H and Kemler R: Cadherin-catenin complex: Protein interactions and their implications for cadherin function. J Cell Biochem 61: 514-523, 1996.

24. Shapiro L, Fannon AM, Kwong PD, Thompson A, Lehmann MS, Grübel G, Legrand JF, Als-Nielsen J, Colman DR and Hendrickson WA: Structural basis of cell-cell adhesion by cadherins. Nature 374: 327-337, 1995.

25. Canel M, Serrels A, Frame MC and Brunton VG: E-cadherin-integrin crosstalk in cancer invasion and metastasis. J Cell Sci 126: 393-401, 2013.

26. Liu DS, Hoefnagel SJM, Fisher OM, Krishnadath KK, Montgomery KG, Busuttil RA, Colebatch AJ, Read M, Duong CP, Phillips WA and Clemons NJ: Novel metastatic models of esophageal adenocarcinoma derived from FLO-1 cells highlight the importance of E-cadherin in cancer metastasis. Oncotarget 7: 83342-83358, 2016.

27. Strathdee G: Epigenetic versus genetic alterations in the inactivation of E-cadherin. Semin Cancer Biol 12: 373-379, 2002.

28. Vécsey-Semjén B, Becker KF, Sinski A, Blennow E, Vietor I, Zatloukal K, Beug H, Wagner E and Huber LA: Novel colon cancer cell lines leading to better understanding of the diversity of respective primary cancers. Oncogene 21: 4646-4662, 2002.

29. Kanazawa T, Watanabe T, Kazama S, Tada T, Koketsu S and Nagawa H: Poorly differentiated adenocarcinoma and mucinous carcinoma of the colon and rectum show higher rates of loss of heterozygosity and loss of E-cadherin expression due to methylation of promoter region. Int J Cancer 102: 225-229, 2002.

30. Cheng CW, Wu PE, Yu JC, Huang CS, Yue CT, Wu CW and Shen CY: Mechanisms of inactivation of E-cadherin in breast carcinoma: Modification of the two-hit hypothesis of tumor suppressor gene. Oncogene 20: 3814-3823, 2001.

31. Shen Y, Hirsch DS, Sasiela CA and Wu WJ: Cdc42 Regulates E-cadherin ubiquitination and degradation through an epidermal growth factor receptor to Src-mediated pathway. J Biol Chem 283: 5127-5137, 2008.

32. Symowicz J, Adley BP, Gleason KJ, Johnson JJ, Ghosh S, Fishman DA, Hudson LG and Stack MS: Engagement of collagen-binding integrins promotes matrix metalloproteinase-9-dependent E-cadherin ectodomain shedding in ovarian carcinoma cells. Cancer Res 67: 2030-2039, 2007. 
33. Johnson SK, Ramani VC, Hennings L and Haun RS: Kallikrein 7 enhances pancreatic cancer cell invasion by shedding E-cadherin. Cancer 109: 1811-1820, 2007.

34. Trillsch F, Kuerti S, Eulenburg C, Burandt E, Woelber L, Prieske K, Eylmann K, Oliveira-Ferrer L, Milde-Langosch K and Mahner S: E-cadherin fragments as potential mediators for peritoneal metastasis in advanced epithelial ovarian cancer. Br J Cancer 114: 213-220, 2016.

35. Jang B, Jung H, Chung H, Moon BI and Oh ES: Syndecan-2 enhances E-cadherin shedding and fibroblast-like morphological changes by inducing MMP-7 expression in colon cancer cells. Biochem Biophys Res Commun 477: 47-53, 2016.

36. Carvalho S, Oliveira T, Bartels MF, Miyoshi E, Pierce M, Taniguchi N, Carneiro F, Seruca R, Reis CA, Strahl S and Pinho SS: O-mannosylation and N-glycosylation: Two coordinated mechanisms regulating the tumour suppressor functions of E-cadherin in cancer. Oncotarget 7: 65231-652446, 2016.

37. Petrova YI, Schecterson L and Gumbiner BM: Roles for E-cadherin cell surface regulation in cancer. Mol Biol Cell 27: 3233-3244, 2016.

38. Okugawa Y, Toiyama Y, Inoue Y, Iwata T, Fujikawa H, Saigusa S, Konishi N, Tanaka K, Uchida K and Kusunoki M: Clinical significance of serum soluble E-cadherin in colorectal carcinoma1. J Surg Res 175: e67-e73, 2012.

39. Efstathiou JA, Liu D, Wheeler JM, Kim HC, Beck NE, Ilyas M, Karayiannakis AJ, Mortensen NJ, Kmiot W, Playford RJ, et al: Mutated epithelial cadherin is associated with increased tumorigenicity and loss of adhesion and of responsiveness to the motogenic trefoil factor 2 in colon carcinoma cells. Proc Natl Acad Sci 96: 2316-2321, 1999.

40. Kitadai Y, Bucana CD, Ellis LM, Anzai H, Tahara E and Fidler IJ: In situ mRNA hybridization technique for analysis of metastases related genes in human colon carcinoma cells 147 $1238-1247,1995$

41. Gofuku J, Shiozaki H, Tsujinaka T, Inoue M, Tamura S, Doki Y, Matsui S, Tsukita S, Kikkawa N and Monden M: Expression of E-cadherin and alpha-catenin in patients with colorectal carcinoma. Correlation with cancer invasion and metastasis. Am J Clin Pathol 111: 29-37, 1999.

42. Velikova G, Banks RE, Gearing A, Hemingway I, Forbes MA, Preston SR, Hall NR, Jones M, Wyatt J, Miller K, et al: Serum concentrations of soluble adhesion molecules in patients with colorectal cancer. Br J Cancer 77: 1857-1863, 1998.
43. Wilmanns C, Grossmann J, Steinhauer S, Manthey G, Weinhold B, Schmitt-Gräff A and von Specht BU: Soluble serum E-cadherin as a marker of tumour progression in colorectal cancer patients. Clin Exp Metastasis 21: 75-78, 2004.

44. Weiss JV, Klein-Scory S, Kübler S, Reinacher-Schick A, Stricker I, Schmiegel W and Schwarte-Waldhoff I: Soluble E-cadherin as a serum biomarker candidate: Elevated levels in patients with late-stage colorectal carcinoma and FAP. Int J Cancer 128: 1384-1392, 2011

45. Cao H, Xu E, Liu H, Wan L and Lai M: Epithelial-mesenchymal transition in colorectal cancer metastasis: A system review. Pathol Res Pract 211: 557-569, 2015.

46. Wang R, Ma X, Li Y, He Y, Huang D, Cai S and Peng J: The characteristics and prognostic effect of E-cadherin expression in colorectal signet ring cell carcinoma. PLOS One 11: e0160527, 2016.

47. Gao M, Zhang X, Li D, He P, Tian W and Zeng B: Expression analysis and clinical significance of eIF4E, VEGF-C, E-cadherin and MMP-2 in colorectal adenocarcinoma. Oncotarget 7: 85502-85514, 2016.

48. Chen D, Dai F, Chen Z, Wang S, Cheng X, Sheng Q, Lin J and Chen W: Dimethoxy curcumin induces apoptosis by suppressing survivin and inhibits invasion by enhancing E-cadherin in colon cancer cells. Med Sci Monit 22: 3215-3222, 2016.

49. Nguyen L, Fifis T and Christophi C: Vascular disruptive agent OXi4503 and anti-angiogenic agent Sunitinib combination treatment prolong survival of mice with CRC liver metastasis. BMC Cancer 16: 533, 2016.

50. Fan LC, Teng HW, Shiau CW, Tai WT, Hung MH, Yang SH, Jiang JK and Chen KF: Regorafenib (Stivarga) pharmacologically targets epithelial-mesenchymal transition in colorectal cancer. Oncotarget 7: 64136-64147, 2016.

51. Liu S, Barry EL, Baron JA, Rutherford RE, Seabrook ME and Bostick RM: Effects of supplemental calcium and vitamin D on the APC/ $\beta$-catenin pathway in the normal colorectal mucosa of colorectal adenoma patients. Mol Carcinog 56: 412-424, 2017. 